\title{
Discussion on Teaching Method Research and Exploration of the Course of Management
}

\author{
Tang Jian* \\ Management Department, the Engineering \&Technical College of Chengdu University of \\ Technology, Leshan City, Sichuan Province, China \\ email:46851059@qq.com
}

Keywords: management, teaching method, case analysis,case teaching,company simulation.

\begin{abstract}
Management is a professional basic course of economic management and demands to pay equal attention to theories and practices. Thus, if you want to realize good teaching result, you need to reform traditional teaching models and teaching methods. This paper puts forward reform direction and methods of course teaching from the aspect of emphasis on cultivating study interest of students, the ability to solve problems and comprehensive quality and offers some ideas for improving teaching quality and better training and managing applied talents.
\end{abstract}

Management is the science which studies organizational business activities and organization activities and its purpose is to state the general law of business activities and organization activities and provides a kind of guiding framework for organizational business. The course of Modern Management mainly states three levels from low to high: the first level is the connation of management, including management activities, management thoughts and management theories; the second level is management process, including managerial functional activities, such as decision, plan, organization, human resource, leaders, stimulation, communication, control and so forth; the third level is improvement and innovation of management.

Each case in Management enhances a bright subject, and it usually is related to common difficult problems in all kinds of management activities and events which are easy to cause puzzle. It derives from most case practices in society but not only simple memoirs of management activities and it has relatively complete plots and even dramatic contradictions to reflect the process of things happen and changes of roles among people in management practice, and it reveals complexity of management work and cause us to think deeply. Through reading and learning cases, teachers can share successful or falling experience of others, and from studying and analyzing cases of others to reinforcing learning and analyzing yourself, constantly accumulate reflective materials and consciously perfect your own teaching. Because of operability of cases itself, learning management cases can directly drive teachers update educational concepts and improve education and teaching behaviors in the process of reference and study. Through reflecting and summarizing his teaching methods and process, the writer explores the teaching of Management from the following aspects:

\section{Regularize course standards and reasonably arrange course contents}

\subsection{Narrative of development of management theories.}

Formation of previous management theories has an important guiding significance for our follow-up practice activities and this part of narrative makes students realize the formation of subject has a long history and the power of standing on the shoulders of giants. Teaching in the level, according to management theories, should conduct on the basis of venation of time development which starts from embryo and then develops to the stage of classic management theories and modern management theories, and makes students realizes the formation of any theories can separate from the influence of 
temporal social environment. Management theories don't have outmoded or modern statements, but only have the statement of adjusting measures to local conditions and specific situations.

\subsection{Narrative of basic concepts of management.}

On the level, mainly introduce the formation and concepts of management activities and scientificity and artistry of management, objects and environment of management to students, and then lead to the concept of manager. In addition, teachers should introduce basic functions and social responsibilities of management and this part of course has three purposes: the first purpose is to let students realize necessity and significance of the formation of management activities; the second purpose is to make them realize management not only needs inheritance, but also needs innovation; the third purpose is to make them realize a manager with sense of social responsibility is a real manager who pursues excellence.

\subsection{Narrative of management functions.}

In the stage, emphatically introduce basic concept, principles and specific methods of four functions: decision, organization, leader and control to students, and at the same time, state the relationship among the four functions to students and what needs to pay special attention is that can't make students generate the misconception which means that each function is separate because you divide the four functions in the process of teaching and always infuse that each function in management is a systematic concept, making students form correct philosophical view of whole and part. Regularizing course standards and arranging important parts of contents in management according to reasonable order can avoid the possibility that subject knowledge can't validly integrate, and can make students feel it is easy to understand contents of management in the process of listening to the teacher.

\section{Choose more and effective teaching methods of course of Management.}

\subsection{Project teaching method.}

This method is that teachers and students work together to implement teaching activities by a complete project and it combines many kinds of teaching methods and teaching models by a specific project. In the process of the whole project, students need to constantly study, analysis and summary, and based on the combination of theory, summarize learning effect through grasping practical activities when project is finished; it has certain practical value for the teaching method of research project about part of teaching contents. Paying attention to practical teaching can combine theoretical knowledge and practical skills and abilities and guide students to simulate actual productive process or behaviors in real commercial activities. Students have the opportunity to independently plan and implement, and are able to freely organize and arrange their own learning behaviors. There are certain difficulties in the work of project, that is, let them use new knowledge and skills to solve practical problems they never meet. If they overcome the difficulty which appears in the work of project, the project can have a clear and specific result. When the course is over, teachers and students will evaluate together the performance of project.

\subsection{Situational simulation method.}

The so-called method of situational simulation is training and testing decision-making ability of students and adopting "simulation" method to improve their abilities to focus on actual results. For example, we invite certain boss who we have contacted to talk about representative decision problems which their company met in the past years, and then we make students carry out simulation decision aiming at these problems which are offered by the company and its boss. Through these simulations of situational teaching, make students really learn reasonable transform of realistic questions and enhance their abilities to deal with emergencies. 


\section{Correctly use case teaching method.}

When students face contents of a new course, it is hard to avoid for them to generate problems like strangeness of concepts and abstract theories. They mostly hope teachers use case teaching method as much as possible and this kind of suggestion proposes higher demands about teaching designs of teachers. Case teaching method originates from 1820s and was advocated by Harvard Business School, America. Its main content is to adopt a kind of unique form of case to teach, and the majority of cases come from real situation or events of commercial management. This kind of teaching contributes to cultivate and develop students' enthusiasm of participating in class discussion and it has obvious effect after implementing. There are some attentions which are should be paid when using case teaching method: case teaching method is not equal to illustrations. Illustration with example method is a kind of basic model of teaching with single method, and case teaching method is an advanced model of teaching with complex methods which needs to select appropriate and proper cases, otherwise, it will have an exactly opposite effect. However, the premise of these demands to use cases correctly, which requires us to achieve the following points:

\subsection{Increase the input of infrastructure construction of case teaching.}

In view of the situation where infrastructure construction of case teaching is weak in general schools at present, it must increase investment and raise fund through multiple channels and strengthen infrastructure construction of case teaching. The first is establishment of "management simulating lab". Management simulating lab takes advantage of computer technology and multimedia technology to carry out analogue simulation of realistic economic management activities as well as "on-line decision" and "virtual trade" according to economics, management and relevant dynamic analysis methods, making the combination of management teaching and scientific researches and integration of social science and modern information technology become possible, thus improving the whole teaching level. The second is attaching importance to the construction of "management case base". Case is an objective description which is made according to facts. Case teaching focuses on discussion, and its charm lies in "cause deep thinking and brainstorm" and the great part is students advise others by using experiences of others and personally experience the scene and get into the role, thus better arousing the enthusiasm of study of students.

\subsection{Make great efforts to improve the capacity of students to adapt case teaching.}

According to the teaching experience of Harvard Business School, America, the writer thinks the key to improve the capacity of students to adapt management case teaching lies in two points: the first is less teaching and more learning and pay more attention to discussion in order to improve students' adaptive capacity, that is, teachers talk less about contents of books in class and demand students to more study by themselves after school. In the class, mainly discuss cases and make students form study groups to together complete case analysis and research projects of course. The second is high-intensity self-study and exercise in order to strengthen adaptive capacity of students. The majority of course need to have research topics which take study groups as a unit and then the group or the whole members make a speech after finishing a research topic, and case analysis or homework which is individual dominated is made a speech by individual. Through this kind of training process of speech, improve students' ability of speaking and talking.

\section{4. strengthen students' consciousness of entrepreneurship and employment.}

At present, students' employment situation is increasingly serious, and "the craze for graduate school" and "craze for Civil Service Examination" have become choice of last resort, but the number of students who succeed is limited and the rest students are picked and chose in human resource market. In fact, students' employment should not be limited to these ways and they should have more choices. Reflect the higher education which students receive during four years and in addition to a shortage of employment ability of students, the loss of their education about consciousness of 
entrepreneurship is also an important factor. As a student who majors in management, in addition to the study of management theories, he also should be equipped with consciousness of entrepreneurship. As a professional teacher of management, he should encourage students to have a deeper understanding of policies and regulations which are issued by our country to support entrepreneurship and successful cases of starting up business, and combine the accomplishment of teaching tasks and attention about students' employment and reinforce students' consciousness of entrepreneurship. However, during the days in school, possessing consciousness of entrepreneurship does not means that students must start up business, but makes them have one more choice of employment in the future.

The basic task of higher education is to cultivate comprehensive talents with professional knowledge and operational ability. In the process of course teaching experience and exploration about principles of management, it should set up scientific and reasonable teaching ideas and uses ideas to guide whole teaching links of teachers and combines the accomplishment of teaching tasks and improvement of students' ability. Only do that can higher education achieve the task of educating people.

\section{Ideas of action, enhance practical teaching of company simulation.}

The nature of Management not only demands to pay attention to theoretical knowledge, but also should strengthen practical activities. In terms of the major of management, practical teaching method of company simulation is an effective practical educational method. As a practical teaching organizational form of the major of management, students can undergo entire operating process of company through this method and know about its relation among links and make it clear, including emergencies and risk environment they possibly face. This kind of teaching method of company simulation is a method of study on "place of work".

\section{Summary}

In teaching process, the link of "management of simulation company" can be added. From the beginning of studying the course, divide students in the class into several groups and demand each group to found a practice firm and set up its goal, mission and structure chart of its framework and make students clear about their role, and demand each "company" to always pay attention to reality industry trends and timely adjust ideas, tasks, structure and staff. Through this kind of activity, make students feel organizational operation mode and flow, problems about labor division and cooperation and the influence of environment on organizational development and make them better understand the connotation of "management" and lay a foundation for them who really enter into workplace in the future.

\section{References}

[1] Xu Meiling. First Exploration about Teaching Method Reform of Management [J] Commercial Culture (second half of this month), pp. 124, 2012. (12);

[2] Li Mingbo. Application of Case Teaching Method in Courses of Business Administration [J] Business Condition Science Educator, 2007, (11)

[3] Liu Jun. Exploration and Practice about Teaching Method of Course of Management [J] Shandong Textile Economy, 2012 (4)

[4] Li Jianqiao. Discussion about Innovation of Open Teaching Model of Course of Management[J] China Out of School Education, pp.107, 2013(5) 